\title{
Contrato coletivo de trabalho $\left(^{*}\right)$
}

\section{Cesarino Júnior}

\begin{abstract}
Sumário: 1 História. - 2 Denominação. - 3 Definição. - 4 Natureza jurídica. - 5 Interpretação do contrato coletivo. - 6 Aplicaçâo do contrato coletivo. 7 Conteúdo do contrato coletivo. - 8 Estipulação dos contratos coletivos. - 9 Extensão da eficácia do contrato coletivo. - 10 Penalidades.
\end{abstract}

1 - No moderno direito social a organização dos sindicatos tende, em todos os países, para a celebração dos contratos coletivos de trabalho. Não significa isto, porém, que sempre tivesse existido êste instituto, como entidade jurídica perfeitamente regulada pela legislação. Assim como os próprios sindicatos, que viveram muito tempo à margem da lei, também os contratos coletivos surgiram espontâneamente, como consequência da reação dos trabalhadores contra a opressão patronal. Com ef eito - a observação é de Sinz HeIMER - "a maior parte do direito operário tem a sua fonte fóra das coleções de leis" (1). Assim diz êle que, nos primeiros tempos, quando o direito estatal não conhecia senâo a coordenação entre indivíduos juridicamente iguais, a emprêsa nutria um direito não-estatal, fundado sôbre a idéia de subordinação, criada pela vontade dominadora de um só o patrão, expressa geralmente no unilateral "regulament(। de oficina" sendo este direito não estatal de dominação o ver-

(*) Capilulo do livro "Direito Social Brasileiro

(1) La théorie des sources du droit et le droit ouvrier, in Annuaire de l'Institut de Philosophie du Droit et de Sociologie Juridique, v. I, 1934, pg. 78. 
dadeiro direito operário dos primeiros tempos do capitalismo. A forma hierárquica do direito não estatal sucede a forma coletiva do contrato de trabalho. Os agrupamentos de trabalhadores tiram à relação de trabalho o caráter de criação unilateral. Assim, o direito coletivo se revelou por ter saído do jôgo das fôrças sociais e não de uma autorização legal. "As normas regulamentando as convenções coletivas nasceram elas próprias fóra da lei”. O Estado, a princípio se defendeu contra êste dineito não estatal, depois o transformou por regras imperativas, passando depois a reconhecê-lo, como aconteceu particularmente com as diversas leis que regulamentam as convenções coletivas de trabalho. Estas leis tiveram, com ef eito, por fim, garantir o funcionamento jurídico do direito coletivo, chamado à vida por energias extraestatais". Este reconhecimento apresenta diversos graus : "O Estado pode contentar-se em "constatar" a legalidade das convenções : resolve, então, por disposições positivas, as dúvidas que a sua aplìcação jurídica póde fazer nascer delas. Mas o Estado póde ir mais longe : põe à disposição dos operários os quadros que favorecem a conclusão das convenções (órgãos de conciliação) ; substitue às convenções a arbitragem obrigatória; enfim, póde estender sua ação além do círculo dos interessados na convenção (declarando obrigatórias para todos certos contratos de tarifas)" Mas, na Itália fascista o Estado sujeitou o direito não estatal, impondo uma ordem coletiva da profissão, enquanto que na Aỉemanha nazista suplantou o direito não estatal, por isso que lá o "comissário do trabalho" é ao mesmo tempo ditador do Estado no que concerne às condições coletivas do trabalho e do salário, de modo que, sem modificação intrínseca, as convenções coletivas mudaram de natureza, por isso que as forças livres que lhes serviam de fundamento, desapareceram. Esta, a esplêndida síntese que Sinzheimer faz da evolução do contrato coletivo de trabalho.

2 - Aí vimos empregados, como sinónimas, três denominações: convenções coletivas de trabalho, contratos coletivos 
de trabalho e contratos de tarifa (2). A primeira é usada pela legislação francesa e, no Brasil, pelo dec. n. 21.761, de 25 de agôsto de 1932, pela Constituição de 1934, art. 121, § 1., letra $j$ e pela Constituição de 1937, arts. 61, letra $c, 137$, letras $a$ e $b$ e 138, que entre nós regulam o assunto; a segunda legislação italiana e a terceira pela legislação alemã (Tarifvertrag).

Pensamos que qualquer das duas primeiras se prestaria bem para designar o instituto entre nós, mas preferiríamos a segunda, pelo seu caráter de oposição ao contrato individual de trabalho. Contra ela, porém, se insurgem alguns autores, como entre nós Oliveira Viana e Orlando Gomes, afirmando que ela se confunde com outra denominação, a do contrato de trabalho coletivo, contrato de trabalho por turmas, em francês, contrat d'équipe ou marchandage, de que é exemplo típico entre nós o "muchirão", isto é, um feixe de contratos individuais de trabalho, ou, como prefere Gallart Folch, de contratos singulares de trabalho, sendo que êste autor fala também em "convenções coletivas de condições de trabalho"

Sendo a expressão contrato coletivo de trabalho já bastante difundida, com o sentido próprio que lhe damos neste capítulo, julgamos que não há o perigo da alegada confusão, confusão esta que se nota sim em relação às convenções coletivas, visto como. entre nós, recebem tal nome as convenções para prorrogação do horário de trabalho, que, lécnicamente, não se podem chamar de convenções coletivas de trabalho.

3 - A melhor definição de contrato coletivo de trabalho, que conhecemos, é a do art. 1., da lei búlgara de 1936: "O contrato coletivo de trabalho é uma convenção entre representantes de sindicatos de trabalhadores, legalmente constituídos, e patrões isolados ou representantes dos seus

(2) Além destas, outras denominações têm sido propostas para a instituição, embora sem êxito. Assim Costamagna fala em acôrdo corporativo; VierTe, em pacto normativo; e certos autores alemães cin convenção normativa. 
respectivos sindicatos profissionais, tambem legalmente constituídos, cujo objeto é fixar o conteúdo dos futuros contratos individuais (singulares ou coletivos) a serem ajustados entre operários e patrões". Oliveira Viana precisa bem a distinção entre o contrato individual e o coletivo, esclarecendo que no primeiro se pactuam serviços e no segundo normas a serem seguidas pelos futuros contratos individuais de trabalho. (3)

Não é tão acertada a definição do nosso direito (Art. 1. ${ }^{\circ}$ do citado dec. n. 21.761, de 1932) que, baseado na lei francesa de 25 de março de 1919, art. 31, estabelece: "Entendese por convenção coletiva de trabalho o ajuste relativo às condições de trabalho, concluído entre um ou vários empregadores e seus empregados, ou entre sindicatos ou qualquer agrupamento de empregadores e sindicatos ou qualquer outro agrupamento de empregados" Com efeito, já antes da Constituição de 1937 era discutível a validade das pseudoconvenções coletivas, isto é, das celebradas por agrupamentos inominados de empregados, sem personalidade jurídica. Assim, Helvécio Xavier Lopes, escrevendo sôbre o assunto em 1935, dizia: "Não obstante a letra do art. $1 .^{\circ}$, é discutível a validade das convençôes coletivas celebradas pelos agrupamentos inominados de empregados. A redação dêsse artigo se originou, provàvelmente, do art. 31 da lei francesa, de 25 de março de 1919, que define a convenção coletiva como um "contrato relativo às condições de trabalho concluído entre, de uma parte, os representantes de um sindicato profissional ou de qualquer outro agrupamento de empregados, e de outra parte, os representantes de um sindicato profissional ou de qualquer outro agrupamento de empregadores, ou vários empregadores, contratando a título pessoal, ou mesmo um só empregador" (4). No mesmo sentido são as definições de Paul PIc e dos Serviços Técnicos da Repartição Internacional do Trabalho, do Código Federal Suíço das Obri-

(3) Problemas de Direito Corporativo, Rio, 1938, pg. 123.

(4) A Convenção Coletiva de Trabalho na Legislação Brasileira, Rio, 1936, pg. 26. 
gações e da lei rumena de 1929. Ora, hoje a Constituição consagra princípios diametralmente opostos, dispondo, no art. 137, letra $a$ : "Os contratos coletivos de trabalho, concluídos pelas associações legalmente reconhecidas de empregados. "; e 138: "Sómente, porém, o sindicato regularmente reconhecido pelo Estado tem o direito de estipular contratos coletivos de trabalho. ". Assim, cabe definir a convenção coletiva de trabalho, mesmo para o nosso direito, como o faz o citado art. $10^{\circ}$ da lei búlgara de 1936.

Concordam com essa definição a dada pela lei chilena de 8 de setembro de 1924, assim como as formuladas pelos autores italianos, como Fantrini, Barassi, e principalmente Greco, que define: "Contrato coletivo de trabalho é o ato pelo qual duas associações sindicais, nos limites de sua representação, em virtude dos poderes que lhes são conferidos pela lei, instituem mediante acôrdo, um regulamento das relações de trabalho, obrigatório para todos os membros da categoria representada"

4 - Qual a natureza jurídica do contrato coletivo de trabalho? E' êste um dos problemas mais controvertidos em direito corporativo. Em regra as opiniões a respeito se podem classificar em três correntes: contratualista, normativista e mixta.

A primeira, que afirma ser o contrato coletivo de trabalho um contrato, pertencente ao direito comum das obrigações, alguns autores até lhe negando o normativismo jurídico, se filiam, na Itália, Barassi, Sacerdoti, Raneletti, Navarrá, Asquini, Azzariti, Roveli, Greco, Melloni, Zangara, la lumia, Chiarelli, Peretti-Griva, De Semo, Toesca, Pacinotti, Sette, Vassalli e Ruggiero, e grande número de autores franceses e alguns alemães. (6)

(5) Contrato Colletivo di Lavoro, Milão, 1936, pg. 15.

(6) Gallart Folch divide as teorias em: civilistas, ecléticas ou de transição e juridico-sociais. No primeiro grupo inclue as: do mandato, da gestão de negocios, da estipulação em favor de terceiros, do contrato inominado e da personalidade moral fiticia. No segundo as: do pacto social, da solidariedade necessaria, da re- 
Assim, a chamada "teoria do mandato" explica, com Bergson, que o sindicato ao estipular um contrato coletivo representa os seus membros, em virtude de um mandato resultante da adesão dêsses membros aos estatutos do sindicato, enquanto para Hubert-Valleroux, o mandato é conferido ao sindicato pela lei, a qual the permite defender os interêsses profissionais, estipular em nome dos operários e representá-los no contrato. Esta última opinião é sustentada contra o parecer de Dario Guidi também por Barassi, RaNelletti, LA Lumia e Donati, assim como, para a Itália, tambem por Gallart Folch, em vista do disposto no art. 5 da lei italiana de 3 de abril de 1926: "As associações legalmente reconhecidas têm personalidade jurídica e representam todos os empregadores, trabalhadores, artistas ou profissionais da categoria em que se tenham constituido, estejam ou não na mesma inscritos, em todo o âmbito da circunscrição territorial em que operam", dispositivo êste mais ou menos transcrito na declaração VI da "Carta del Lavoro". E' êste o sistema seguido pelo direito brasileiro, conforme a opinião do Prof. Waldemar Ferreira, que é também a nossa. (7) Com efeito, o art. 138 da Constituição de 1937, que, conforme já vimos, se inspirou na lei italiana, dá ao sindicato, que é o representante legal da categoria de produção para que foi constituído, a atribuição de estipular contratos coletivos de trabalho obrigatórios para todos os seus associados. Esta afirmação é reforçada pela da letra $\alpha$ do art. 137 da mesma Constituição: "Os contratos coletivos de trabalho concluídos pelas associações legalmente reconhecidas de empregadores, trabalhadores, artistas e especialistas, serão aplicados a todos empregados, trabalhadores, artistas e especialistas que elas representam" Aliás, a representação legal dos sindicalizados pelo sindicato não seria grande novidade em direito: ela existe há muito civilmente, como demonstrou BA-

presentação legal e do êrro ou costume industrial. No terceiro as teorias: da lei delegada, a sindicalista integral e do ordenamento corporativo. Por motivos óbvios não desenvolveremos nesta rápida sintese, todas essas teorias.

(7) A Justiça do Trabalho, São Paulo, 1938, vol. I, pg. 60. 
RASSI, nos casos do curador ao ventre, do curador da herança jacente e do curador das massas falidas, como casos de representação consentidos pela lei com respeito a pessoas inexistentes ou anônimas no momento em que a relação é instaurada. A' teoria do mandato se prenderia ainda, segundo o Prof. Irineu Machado, a "vertrestrungstheorie de Lotmar, segundo o qual o sindicato intervém no contrato como intermediário dos operários que se obrigam individualmente.

Galizia sustenta a teoria da "gestão de negócios": o sindicato contrata por sua própria iniciativa, mas no interêsse de seus membros, beneficiando-se os operários pela sua permanência ou posterior entrada no sindicato o que implica numa ratificação, ou exonerando-se pela sua demissão.

Raynaud (teoria da "estipulação em favor de terceiros") afirma que o sindicato operário (estipulante) firma com um ou mais empregadores (prometedores ou promitentes) as condições de um acôrdo coletivo contendo cláusulas em favor de "terceiros", os sindicalizados ou membros da categoria (beneficiários). Assim, atuando os sindicatos como gestores de negócios, os efeitos de sua atuação devem reger-se pelas normas do quasi-contrato.

Segundo resume o Prof. Irineu Machado, Nast, na teoria da personalidade moral fitícia, identifica o sindicato com os operários que já o constituem e os considera como partes no contrato, ao qual darão a sua adesão os membros que de futuro nele vierem a inscrever-se (8). Deslandres procura incoerentemente conciliar o mandato e a estipulação em favor de terceiros, na toria da "forma contratual complexa"; considerando o sindicato: "um mandatário que fôsse ao mesmo tempo parte no contrato e que também concluísse em nome de outrem, como o é quem estipula em favor de terceiro"

RouAsr, na "teoria da solidariedade necessária", dá como fundamento ao contrato coletivo de trabalho o princípio da solidariedade. Por sua vez Lambert, Pic e Garraud pro-

(8) Contrato Coletivo de Trabalho, in Boletim do Ministerio do Trabalho, n. 41, de janeiro de 1938, pg. 73. 
curam assimilar o contrato coletivo aos usos ou costumes industriais, no que são criticados por Gallart Folch.

Entre as teorias normativas sobressai a do "pacto social" de DE Vischer, para quem entre trabalhadores e empregadores não há contrato, mas coincidência de interêsses e por isto o acôrdo sôbre condições de trabalho é um "ato complexo", da mesma natureza que a fundação de uma associação, sendo, portanto, uma "convenção-lei", um "ato-regra", uma "lei profissional", disciplinando de maneira objetiva e permanente as relações profissionais entre duas ou mais categorias. Ao entrar no sindicato o patrão e o operário se submetem antecipadamente às decisões da maioria. Nisto é êle seguido, mais ou menos, por CREPIN.

Finalmente, a teoria da instituição corporativa explica a eficácia ultra contraentes do contrato coletivo, que é o ponto nevrálgico da questão, pelo caráter institucional do sindicato, ao qual se une uma certa soberania, que faz com que o contrato coletivo seja uma lei profissional oferecida à adesão dos operários admitidos ao trabalho.

Entre as teorias mixtas se incluem a de Carnelutti seguido por Ascarelli, Rovelli, Montessori, Stolfi, Pergolesi e Romano, que se tornou o seu mais forte defensor e que o considera um contrato híbrido, com "corpo de contrato e alma da lei"; a de Giorgio de SEmo, que vê nele um "negócio jurídico contratual, mas radicado no fecundo e multiforme terreno do direito público"; e Gracco D'Agostino que aproximadamente como SALEMI nele admite duas partes: uma, contendo as obrigações que as associações legalmente reconhecidas assumem reciprocamente (atto negoziale) e outra que contém verdadeiras normas jurídicas (atto normativo).

Mais ou menos a esta teoria aderiu a jurisprudência italiana, decidindo a Côrte de/ Cassação que "o contrato coletivo de trabalho, embora entrando, sob um certo aspecto, no campo do direito público, tem, entretanto, a estrutura intrínseca de um regulamento contratual, preordenado à disciplina das relações de trabalho, de forma que, em caso de controvérsia, compete ao magistrado do mérito interpretar, com 
apreciação soberana, o seu conteúdo e alcance" (9). Esta decisão tem uma importância excepcional, pois, sôbre mostrar a importância prática da solução do problema da natureza jurídica do contrato coletivo de trabalho, dispondo que o mesmo não pode ser apreciado em recurso extraordinário (ricorso per cassazione), por se tratar de uma quaestio facti e não de uma quaestio juris, demonstra ademais que a Suprema Côrte italiana repele a teoria normativa.

E' claro que a tese contratual, à qual aderimos, afirma ser o contrato coletivo um contrato de direito público, cuja eficácia em relação a indivíduos diversos dos que o estipularam se explica pela relação de representação legal dos membros da categoria por parte das associações profissionais. Nisto estão de acôrdo todos os contratualistas.

Admitimos, entretanto, com um certo ecletismo, a existência de um aspecto regulamentar no contrato coletivo de trabalho, quando se dá a sua extensão por ato do Ministro do Trabalho (no regime do dec. n. 21.761, de 1932, art. 11), ou da Justiça do Trabalho (no regime do decreto-lei 1.237, de 1939).

Aí, evidentemente, a obrigatoriedade do contrato coletivo de trabalho, em relação aos indivíduos atingidos pela referida extensão tem um carter heterónomo, pois, resulta, não de um acôrdo de vontades, mas de um ato do poder público. Assim sendo, sómente no sistema do direito italiano, em que não existe essa extensão por ato do poder público, obrigando o contrato coletivo de trabalho, originariamente, a todos os membros da categoria, por força apenas da representação legal atribuida ao sindicato, é que tem plena aplicação a tese contratualista. Já não se póde dizer o mesmo em relação ao direito francês, e ao brasileiro, por exemplo.

Ao contrário, entre os partidários da teoria normativa reina o mais perfeito desacôrdo. Assim, uns consideram o contrato coletivo de trabalho regulamento independente

(9) Giurisprudenza Comparata di Diritto Corporativo Sindacale e del Lavoro, vol. I, fasc. 2, pg. 202, 1937. 
(Guidi), outros regulamento delegado (Betri, Zanobini), outros ainda, regulamento executivo das leis corporativas ( $\mathrm{SA}_{\mathrm{A}}$ LEMI). Divergem também quanto ao fundamento jurídico de sua obrigatoriedade: assim ZANOBINI o coloca no princípio de autonomia de certos entes autárquicos, ao passo que a maior parte dos escritores (Costamagna, Greco, Pergolesi, Vitta, Page) acena a um poder regulamentar. Sermonti, Guidotri, Mazzoni sustentam que o contrato coletivo de trabalho é uma figura nova de fonte de direito que não póde encontrar sistematização em nenhuma das categorias conhecidas antes da reforma sindical.

Tudo indica, portanto, a maior segurança da teoria contratual, principalmente tendo em vista que, como explica o Prof. Conso (10), não se contesta a existência do contrato de direito público. Ademais, desapareceu a distinção romanística entre convenção e contrato: hoje, convenção, isto é o acôrdo de vontades, é sinônimo de contrato e o contrato se identifica com o consenso, com ensina De RugGero: "todo acôrdo sôbre um objeto de interêsse jurídico se torna contrato e é sem mais protegido pelo ordenamento jurídico, qualquer que seja o nome ou a natureza da ação em que esta tutela se concretiza" Assim se tem o contrato normativo, destinado a disciplinar preventivamente o conteúdo de sucessivos eventuais contratos, categoria geral a que, além do contrato coletivo, pertencem o contrato-tipo e o contrato de adesão.

Entre os efeitos da construção jurídica que atribue aó contrato coletivo caráter contratual aponta o Prof. Conso os seguintes: $a$ ) as regras de interpretação do contrato coletivo, que são as dos contratos e não as das leis; $b$ ) inadmissibilidade da aplicação analógica; c) a inapreciabilidade (incensurabilitá) do contrato coletivo pela Côrte de Cassação.

Na Alemanha, antes de 1918, os efeitos do contrato coletivo eram explicados pelas teorias apontadas da representa-

(10) Rev, cit., pg. 206. 
ção, do contrato a favor de terceiros (Lotmar, Sineheimer), não sendo inderrogáveis as suas normas, ao contrário do que já então dispunha o Código Civil Suíço de 1911, no art. 232. Este princípio foi estabelecido pelo decreto de 23 de novembro de 1938 (Tarifvertragsverordnung), que dava ao Ministro do Trabalho a faculdade de ordenar a sua obrigatoriedade geral. Decretos de 3 de setembro de 1919 e de 30 de outubro de 1923 deram às comissões de conciliação a faculdade de declarar obrigatório o seu laudo. Aplicavam-se então à ordnung tôdas as normas relativas aos decretos emanados de um órgão público competente. HuEcK-NipperdeEy, KassKEL, KASKeL-Dersh, contra a opinião de JACOBI afirmam que então o contrato coletivo se devia considerar como fonte do direito objetivo. Assim o Reichsarbeitsgericht (Tribunal Imperial do Trabalho) podia cassar, em revisão, a interpretação dada ao contrato coletivo pelos juizes do mérito. A lei sôbre o ordenamento do trabalho nacional de 1934, substituíu à Tarifvertrag a Tarifordnung, que é lei em sentido substancial, emanada de um órgão público.

No direito francês domina ainda a teoria privatística. A situação antes da guerra era a mesma alemã de antes de 1918. A lei de 1919 estabeleceu a inderrogabilidade. Faltavam a possibilidade de arbitragem obrigatória e da declaração de obrigatoriedade geral. Recentemente êste poder foi concedido ao Ministro do Trabalho pela lei de 24 de junho de 1936. que introduziu também o processo de conciliação. tentando-se assim, na frase de Capitant e Cuche, dar ao contrato coletivo "um caráter institucional" Completaram estas medidas a lei de 31 de dezembro de 1936, o decreto de 16 de janeiro de 1937, que, embora em caráter provisório, estabelecem essa obrigatoriedade por ato do Ministro do Trabalho.

5 -- Já dissemos que a interpretação dos contratos coletivos deve ser a dos contratos e não as das leis. E' esse um efeito de sua natureza contratual. Na Itália deriva também de disposição expressa de lei : o art. 16, da lei de 3 de abril de 1926, pelo qual: "a Magistratura do trabalho julga na aplicação dos pactos existentes segundo as normas de lei sôbre a 
interpretação e execução dos contratos" Azzaritr refutou com vantagem a tése de que o contrato coletivo deveria sujeitar-se a um duplo critério de interpretação: o dos contratos, para as controvérsias coletivas, e o das leis, para as individuais.

Na nossa legislação não há disposição alguma a respeito. Entretanto, dada a idenţidade de situações da nossa e da legislação italiana, quanto à natureza jurídica do contrato coletivo, (que em nosso direito é ainda mais contratual por isso que os contratos coletivos não são automaticamente obrigatórios para tôda a categoria, como na Itália, mas tão sòmente para os associados dos sindicatos contratantes) seguese que se devem aplicar os mesmos princípios estabelecidos pela doutrina italiana e acima expostos resumidamente.

6 - O contrato coletivo de trabalho, segundo a lição de BARASSI se aplica sòmente às relações de trabalho, entre classes diferentes de uma mesma categoria, isto é, entre empregadores e empregados, não sendo admissivel um contrato coletivo entre sindicatos só de empregados, ou entre sindicatos só de empregadores.

Éstes princípios, em nossa lei, decorrem da própria definição contida no art. $10^{\circ}$ do dec. 21.761 e no art. 137, letra $a$, da Constituição. Esste inciso afirma, com efeito: "Os contratos coletivos de trabalho concluídos pelas associações legalmente reconhecidas de empregadores, trabalhadores, artistas e especialistas, serão aplicados a todos os empregados, trabalhadores, artistas e especialistas que elas representam", não falando, no final, inexplicàvelmente em empregadores.

7 - Na forma do art. 6. ${ }^{\circ}$ do dec. 21.761, as convenções coletivas, que, de acôrdo com a técnica da Constituição devemos chamar e chamamos, sempre, mesmo quando nos referirmos ao citado decreto, de contratos coletivos de trabalho, devem conter obrigatoriamente: a designação precisa dos contratantes; o serviço ou os serviços a serem prestados e as categorias de empregados que os prestarão; o local ou os locais do trabalho, a fixação dos salários ou ordenados e a for- 
ma do seu pagamento - se por unidade de tempo ou de obra, por tarefa ou qualquer outra maneira; a duração do ajuste, que pode ser determinada, indeterminada ou para especificado serviço; a forma e condições para rescisão, revogação ou alteração da convenção.

A Constituição, no art. 137, letra $a$, é menos exigente, dispondo que os contratos coletivos deverão estipular obrigatoriamente a sua duração, a importância e as modalidades do salário, a disciplina interior e o horário do trabalho.

E' evidente que essa enumeração não exclue outras cláusulas, como as referentes às normas para a solução pacífica das divergências surgidas entre os contratantes. $O$ art. $7 .^{\circ}$ do decreto, depois de se afirmar no art. 6. letra $d$, ser obrigatório consignar a duração do ajuste, dispõe absurdamente que a vigência das convenções coletivas; salvo estipulação em contrário, será de um ano, considerando-se prorrogada se não houver denúncia 30 dias antes de expirado o prazo, nenhum contrato podendo durar mais de quatro anos, podendo, porém, o contrato coletivo por tempo indeterminado ou prorrogado tacitamente, ser denunciado por qualquer das partes, assim como podendo dele desligar-se qualquer membro do grupo contratante, com aviso pelo mesmo prazo. Será reputado concluído o contrato estipulado em vista de determinado serviço, uma vez êste concluído. Poderá o contrato ter a sua execução suspensa em caso de fôrça maior, como falta de matéria prima, energia ou fôrça motriz, acidentes coletivos, epidemias, crises que acarretam escassez de fundos ou de encomendas, etc., caso em que as Comissões de Conciliação poderão prorrogá-los por tempo equivalente.

8 - Para a estipulação dos contratos coletivos, nos termos do art. $1 .^{\circ}$, do dec. 21.761 , os sindicatos ou federações sindicais e associações de empregadores e empregados deverão estar autorizados por expressa disposição dos estatutos ou por deliberação de assembléia geral especialmente convocada para êsse fim, e com ratificação de outra assembléia pur maioria de dois terços de associados, ou em terceira convocação, nos termos dos estatutos. 
Deverão ser celebrados por escrito em três vias, sem emendas, nem rasuras, assinadas pelos contratantes e por duas testemunhas, ficando cada parte com uma das vias e sendo a outra via remetida, dentro de 30 dias da assinatura, ao Ministério do Trabalho, onde, assim como as prorrogações, será registrada e arquivada, devendo suas cópias autênticas ser afixadas nas sédes dos grupos contratantes. Os contratos entrarão em vigor 30 dias após a assinatura, salvo estipulação em contrário. Daí por diante obrigam também aos grupos que vierem a aderir, da mesma profissão e região com o consentimento dos contratantes e mediante registro no Ministério. Igualmente obrigam aos componentes do grupo, que só poderão exonerar-se de qualquer compromisso deleresultante, desde que não o hajam ratificado, seja por votar contra êle ou por ausência à assembléia ratificadora, demitindo-se por escrito do grupo, no prazo de 10 dias da data da assembléia.

9 -- Como acabamos de ver o sistema da lei brasileira é muito diferente do italiano, em que os contratos coletivos. obrigam desde logo a todos os membros da categoria a que pertencem os sindicatos contratantes, como se vê na declaração 3." da "Carta del Lavoro", ao passo que entre nós, mesmo no sistema da Constituição de 1937, art. 137, letra $a$, se vê que se aplicam a todos os "empregados, trabalhadores, artistas e especialistas que elas representam e que devem ser sòmente os seus associados, nos termos do art. 138, que dá, ao sindicato reconhecido pelo Estado, o direito de "estipular contratos coletivos de trabalho obrigatórios para todos os seus associados" Parece-nos, entretanto, pelo menos exquisita esta disposição da lei constitucional, por isso que, representando o sindicato "todos os que participarem da categoria de produção para que foi constituido", como consta do mesmo art. 138 logicamente o contrato celebrado pelos sindicatos de uma determinada categoria, deveria aplicar-se a tôda ela.

A-pesar-disto, quer parecer-nos que a Constituição conservou o sistema do dec. 21.761, de subordinar a extensão da obrigatoriedade do contrato coletivo a um ato do Ministro do 
Trabalho, sistema êste que, embora vigente ainda em vários paises, nos parece evidentemente antiquado e incompativel mesmo como espírito corporativista da Constituição.

Assim, pelo citado decreto, art. 11, o Ministro do Trabalho, ouvida a competente Comissão de Conciliação, poderá tornar obrigatório para os demais empregados e empregadores do mesmo ramo profissional o cumprimento de um contrato coletivo celebrado num ou mais Estados ou Municípios, por três quartos de empregados e empregadores do mesmo ramo profissional, se assim o requerer um dos convenentes, com a indicação dessas circunstâncias e do prazo ajustado. Após publicação do requerimento por 15 dias, o decurso do prazo de 30 dias para plonunciamento dos interessados, e após relatório circunstanciado da Comissão, o Ministro decidirá, podendo sugerir modificações que a Comissão apresentará aos interessados, só podendo adotá-lo após sua aprovação. Deferida a generalização, será publicada no "Diário Oficial", vigorando pelo prazo nela estabelecido ou outro inferior a 4 anos e ficando sem efeito os contratos coletivos anteriores atinentes à mesma atividade profissicnal, salvo nas cláusulas não colidentes com ela e mais favoráveis aos empregados.

10 - Segundo o art. 10 do dec. n. 21.761, os contratos coletivos fixarão multas por infração das cláusulas ajustadas, de maneira que as que tiverem de ser impostas aos empregados ou aos seus sindicatos e agrupamentos sejam sempre inferiores às de que se tornarem passiveis os empregadores ou seus sindicatos e agrupamentos.

Verificada a infração, o infrator será autuado pelo Departamento Nacional do Trabalho ou Inspectorias Regionais, sendo cobrado executivamente se no prazo de 15 dias não a pagar, tendo, porém, direito a recurso com efeito suspensivo para o Ministro do Trabalho dentro dos 30 dias a contar da intimação. A importância destas multas será aplicada nas despesas de fiscalização a cargo do citado Departamento.

Dispõe ainda o art. 13 que as divergências e dissídios resultantes de qualquer infração dos contratos coletivos antes 
de levados ao conhecimento do Ministro, deverão, salvo estipulação em contrário, ser submetidos às Comissões de Conciliação.

Bibliografia - Oliveira Viana, Problemas de Direito Corporativo, Rio, 1938; - Helvécio Xavier Lopes, A Convenção de Trabalho na Legislação Brasileira, Rio, 1936 - Orlando Gomes, A Convenção Coletiva de Trabalho, Baía, 1936 - Alejandro Gallart Folch, Las Convenciones Coletivas de Condiciones de Trabajo en la Doctrina y en las Legislaciones Estranjeras y Española, Barcelona, 1932 Grongro de Semo, Il Contratto Colletivo di Lavoro, Pádua, 1935 Gracco D'Agostino, La Validitá del Contrato Colletivo di Lavoro, Pádua, 1935 - Francesco Carneluttr, La Teoria del Regolamento Collettivo dei Rapporti di Lavoro, Pádua, 1936 - Bureau International du Travail, Les Conventions Collectives, Genebra, 1936 - $\mathrm{H}$. $\mathrm{S}$ NZHeImer, La thérie des sources du droit et le droit ouvrier, in Annuaire de L'Institut de Philosophie du Droit et de Sociologie Juridique, v. I, 1934, pg. 78 - Magnillat, Conventions collectives de travail et arbitrage, Paris, 1936 - Irineu Machado, Contrato Coletivo de Trabalho, in Boletim do Ministério do Trabalho, n. 41, de janeiro de 1938, pg. 73 - Paolo Greco, Il Contratto Colletivo, in Il Diritto del Lavoro, 6-7, de junho-julho de 1937, pg. 185 - René Petit, Les Conventions Collectives de Travail, Paris, 1938 - Gracco D'Agostino, Il Contratto Collettivo di Lavoro, Pádua, 1932 - Pelio Marrani, Il Contratto Collettivo di Lavoro, Pádua, 1935 - Louis Guisan, La place du contract collectif de travail dans le système de droit suisse, Lausanne, 1936 - E. Heinitz, Intorno alla natura giuridica del contratto collectivo, in Giurisprudenza comparata di diritto corporativo sindacale e del lavoro, vol. 1. fasc. 2, de 1937, pg. 198 - P. Conso, Natura giuridica del contratto collettivo e sindacale della Cassazione, citada revista pg. 201 - Gruliano Mazzoni, Teoria dei limiti di applicabilitá dei contratti collettivi di lavoro, Milão, 1939 - Chardes de Visscher. Le Contract Collectif de Travail, Paris, 1911. 